\section{Llegar $y$ auditar-}

El rol que cumplieron los auditores externos en el caso La Polar está marcado por prácticas que dejan mucho que desear, más que por normas que no se cumplieron. Por Juan Foxley Rioseco*. En momentos en que nuestra Facultad
El caso, profusamente descrito. La Polar extendia creditos de consumo $y$ avances ocultaba luego los préstamos impagos dispero al día. Eludía así realizar las debidas provisiones contables, inflando artificial $y$ maliciosamente las utilidades esperadas y el valor de la compañía.

Al daño sufrido por accionistas, tenedores de bonos, prestamistas y ahorrantes en fondos de pensiones, se agregó el insulto de constatar que ejecutivos de la firm vendieron titulos sobrevaluados antes de debacle usando para si mismos la información privilegiada. res morosos sufieron repactaci a tropello a consumidores desinformados, sino también la emisión de una seña allá de los propios medios era no solo poo paga". chaso de la cadena de tiendasta frece una buena oportunidad de análisis forense, y de paso, sirve para recordar importancia de la etica en los negocios. de Economia y Negocios incorpora la carera de Auditoría a su trabajo académico, de esta disciplina para una adecuada preención de irregularidana adestasas. Destacar el rol de los auditores externos no significa, por cierto, ignorar la responsabilidad de otros actores: el directorio de de los clasficadores de restampoco el destacábamos en una edicín anterior de Observatorio Económico ("Estándares pobres", mayo de 20111, suelen llegar tarde y cargados de conflicto de interés a la publicación de sus juicios. En este caso, el trabajo de los clasificadores de riesgo indujo a colocación de bonos.

Pues bien, si b atores no es condición unica, ni siquiera necesaria, si es condición suficiente para detectar irregularidades. En particular, hubiera bastado el desempeno competente de los auditores para potenciar la actuación de al menos las siguientes dos otras bierno corporativo.

SUPERINTENDENCIA EN EL SEGUNDO PISO En el plano regulatorio, la normativa
sobre tarjetas no bancarias establece que la Superintendencia de Bancos e Instituciones financieras (SBIF) tiene el mandato del Banco Central para supervisar a dichos

un capital minimo de UF 200 mil acreditaEn

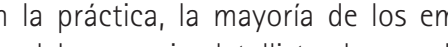
En queda asi en un rol de fiscalización "de segundo piso", en el que la verificación de riesgo se delega a los auditores. La lógca regulatoria implicita aqui es focaliz en la estabilidad del sistema de pagos, y silos proveedores asociados son, como fueron en este caso, pagados dentro do los tres dias de realizada la transacción. ningun riesgo sistemico estaria en juego. Consecuentemente, el regulador se concentra en supervisar directamente solo Tas entidades que captan depositos del puiblico, esto es, los bancos $y$ I Por supuesto, dicha misión de bonos yotros valores de oferta pública son, de alguna forma, pasivos financieros con los que actos irregulares de un emisor pueden amenazar la fe pública y trabar asi la propia fluidez del sistema de pagos. Lo mismo respecto de los créditos de Cajas de Compensación, discusión que estipula que si el emisor efectúa tran- no haremos aqui. anuales y los comercios afiliados en que se puede usar la tarjeta pagan dentro de tres das, la SBlF no está obligada a supervisar ir la certificación de un auditor externo. gir la certiceación de un auditor externo. anual de evaluación de riesgo, además de 
con ello revisar los algoritmos de cálculos que permiten determinar el monto de las revelados en los estados finormaciones provisiones. Pun último, los criterios antes también, una evaluación de los princi... sering entabilidad utilizados y de las estimaauditados (Circular 17, SBIF, Nov. 2006). Ciertamente, pudo ser más proactiva como de hecho lo fue en las semanas posteriores al destape de la estafa- y pudo otras fuentes los informes de riesgo que recibía de los auditores. Sin embargo, la responsabilidad primaria radicaba en la auditoría externa, obligada

\section{¿CRONISTAS O CONTRALORES?}

Respecto a la instancia de gobierno corporativo, los auditores externos juega

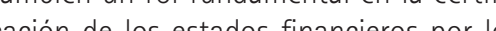
cuales responden personalmente los drectores de la empresa.

Aunque los auditores recuerdan que su labor se limita a emitir una opinión se les ha escuchado declarar que no son investigadores de fraude-, no existe un instancia auxiliar independiente de contro inanciero para el comité de auditoria un directorio que pueda sustituir la tarea de los auditores externos. Para eso se les contrata. Para detectar inconsistencias en definitiva, proteger la responsabilidad
de los propios directores.

Tipicamente, los dictámenes de auditoría propia responsabilided sin guardia de bién son explicitos en el alcance de su taor. Por ejemplo, el informe de los auditores independientes al 15 de marzo de 2011 sobre Empresas La Polar dice lo siguiente: "Una auditoría comprende el examer, a base de pruebas, de evidencias que res- paldan los importes y las informaciones ción mostrada por la empresa. El uso de

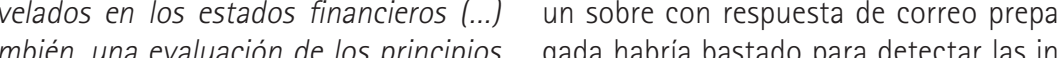
contabilidad utilizados y de las estima- consistencias y eventualmente advertido a lmi- el fraude La empresa y los auditores se nistración...".

Y concluye con el habitual párrafo: "En nuestra opinión, los mencionados estados financieros consolidados presentan razonablemente en todos sus aspectos significativos, la situación financiera consolidada de Empresas La Polar S.A. y subsidiarias al 31 de diciembre de 2010 y 2009 $Y$ al 1 de enero de 2009, los resultados integrales de sus operaciones y los flujos de efectivo por los años terminados el 31 de
diciembre de 2010 y 2009 de acuerdo con diciembre de 2010 y 2009 de acuerdo con Normas In
Financiera":

Dichos estados financieros fueron falsifcados y la SVS no los publicará hasta en adelante. Sabemos, sin embargo que en adelante. Sabemos, sin embargo, que en tió alguna salvedad relevante. En particula respecto la verosimilitud de las provisiones por incobrables, los dictámenes fueron limpios, esto es, aceptados como fiel reflejo de la realidad financiera de la empresa. bría aumentado el precio de la acción no hasu valor original entre 2003 y 2010. Una forma simple de cumplir con la obligación de examinar a base de pruebas yevidencias de respaldo habria sido concito es tan sencillo como habitual envie una carta, como hacen los auditores internos de los bancos respecto de las cuentas corrientes y de inversión a un número reducido de deudores. Esa carta estándar habría permitido verificar si los saldos que tenía el cliente coincidian con la informa- los auditores se

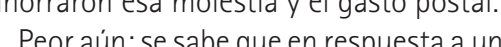
circular de la SVS, La Polar creó en 2007 el. departamento de contraloría interna. No se conoce el detalle de sus informes ni su ubicación jerárquica, pues no aparecen en organigrama publicado en la última Memoria Anual de la empresa. Si se ha conocido que esos informes no eran dirigidos al drectorio sino a dos gerentes de area, lo que importa una clara contravención a la SBIF deba, que el informe de auditoría a la "la función de auditorí mas

Lla furcion de auditaria mantiene una tintos riesgos asociados al proceso crediticio. Esto involucra al menos, la revisión del cumplimiento de politicas y procedimientos, las visitas a sucursales, la revisión de os aspectos operativos asociados al proeso de crédito, del cumplimiento legal y normativo asociado a los procesos de crédito y cobranza y de las herramientas de apoyo a la gestión crediticia. Los informes son entregados al Directorio y se toman las acciones pertinentes para subsanar las debilidades encontradas". (Anexo 1 de la misma circular 17 SBIF, antes citada).

Además, la minusvalía de los auditores buenas prácticas de contralorí independiente internacionalmente aceptadas, que recomiendan la subordinación del auditor interno al directorio (OECD 2004. "PrinciEl trabajo de contraloría interna no fue considerado por el directorio, según refiere la SVS en su formulación de cargos a los pios de gobierno corporativo", numeral D7). responsables. Evidentemente, dicho trabajo tampoco sirvió de insumo a los dictálas auditorías externas.

En suma, los auditores fallaron al menos dos veces por año desde 2003. Primero, cuando entregaban a I SBIF sus informes anuales de riesgo correspondientes la administradora de tarjetas de crédito y luego, cuando emitian sus dictámenes cada abril respecto de los estados financieros de la empresa matriz.

- Hubiera bastado un solo dictamen de auditoría con opinión debidamente verificada para las cuentas por cobrar, para advertir oportunamente a los inversionistas. Hubiera bastado el trabajo bien hecho de los auditores independientes para gatillar los indicios los rectados, pa extra-pola el poder discrecional que la ley les otorga.

el poder discrecional que la rey les otorga REIVINDICAR LA AUDI
TANCIA AUTÓNOMA

ción pública y las pérdidas sufridas por acreedores y accionistas, se suelen exigir cambios drásticos de normativa. A la luz de este artículo, observamos que no son las normas sino las prácticas las que ofrecen mayor espacio

Aparte de la mayor disciplina en los hàbitos y competencia de los directores, rol de auditoria externa e interna deberí por la normativa, tendria más bi pasa peferirse a las sanciones por negligenca que a la imposición de medidas de microgestión desde las superintendencias respectivas.

Asi, por ejemplo, la SVS ha limitado ya los servicios adicionales que los auditores externos pueden vender al cliente rev- sado. Se elimina asi un foco de conflicto de interés por connivencia cuando se les teneduria de libros, tasaciones y valorizaiales, entre otras.

A su turno, una reforma de regulación que refuerce la independencia de juicio de los auditores sería obligar no solo a la rotación de éstos, sino a la nominación a ciegas. Asi, la empresa auditada podría SVS la que asigne la compañía auditora de su registro y por un periodo máximo de dos años, de modo de institucionalizar la rotación. Además, podría exigirse que la auditoria de emisores de tarjetas de crédito sea realizada por una distinta a aquella encargada de emitir los dictá consolidados.

Por último, en aquellas empresas del sector real que tengan negocios financieros sujetos a la regulación de la SBIF, Ios auditores internos (i.e. Gerente Contralor) deberian tener un espacio para reportar su opinión en las notas de los estados financieros trimestrales o, en su defecto, se deberia exigir un pronunciamiento formal de los comités de auditoria del directorio respecto al trabajo reportado por ellos. Son todas normas relativamente simples de implementar, aunque probablemente requieren ajustes legales menores Demostrado está que et controt negligente de riesgos hizo que no fuera "llegar y auditar" La sanidad del mercado de valores exigiría, sin grandes nuevas reformas en lo inmediato, "llegar y legislar" respecto de auditores $y$, latentes en este articulo, clasificadores de riesgo, que están expuestos a los mismos vicios y conflictos potenciales.
Decano: Jorge Rodríguez Gross -mail: jrodrigu@ @uahurtado. Cronomiaynegocios.uahurtado.cl/observato Periodismo UAH. 